This item was submitted to Loughborough's Research Repository by the author.

Items in Figshare are protected by copyright, with all rights reserved, unless otherwise indicated.

\title{
Influence of wheel configuration on wheelchair basketball performance: wheel stiffness, tyre type and tyre orientation
}

PLEASE CITE THE PUBLISHED VERSION

http://dx.doi.org/10.1016/j.medengphy.2015.02.001

\section{PUBLISHER}

(c) Elsevier Ltd

VERSION

AM (Accepted Manuscript)

\section{PUBLISHER STATEMENT}

This work is made available according to the conditions of the Creative Commons Attribution-NonCommercialNoDerivatives 4.0 International (CC BY-NC-ND 4.0) licence. Full details of this licence are available at: https://creativecommons.org/licenses/by-nc-nd/4.0/

\section{LICENCE}

CC BY-NC-ND 4.0

\section{REPOSITORY RECORD}

Mason, Barry S., M. Lemstra, Lucas H.V. van der Woude, Riemer J. Vegter, and Victoria L. Goosey-Tolfrey. 2019. "Influence of Wheel Configuration on Wheelchair Basketball Performance: Wheel Stiffness, Tyre Type and Tyre Orientation". figshare. https://hdl.handle.net/2134/17085. 
1 Influence of wheel configuration on wheelchair basketball performance: wheel stiffness, 2 tyre type and tyre orientation

3

4 Mason B.S ${ }^{a}$., Lemstra $M^{b}$., van der Woude L.H.V ${ }^{b}$, Vegter $\mathbf{R}^{\mathbf{b}}$., Goosey-Tolfrey V.L ${ }^{a}$ 5

$6{ }^{a}$ Peter Harrison Centre for Disability Sport, School of Sport Exercise \& Health Sciences,

7 Loughborough University, Loughborough, UK

$8{ }^{b}$ Centre for Human Movement Sciences, University Medical Centre Groningen, University of 9 Groningen, Groningen, The Netherlands

10

11 Corresponding author:

12 Dr Barry Mason, Peter Harrison Centre for Disability Sport, School of Sport, Exercise \& 13 Health Sciences, Loughborough University, Leics, LE11 3TU, UK.

14 Email - b.mason@lboro.ac.uk

15 Telephone - +44 (0) 1509226387 


\section{Abstract}

17 The aim of the current investigation was to explore the lateral stiffness of different sports 18 wheelchair wheels available to athletes in a 'new' and 'used' condition and to determine the 19 effect of (a) stiffness, (b) tyre type (clincher vs. tubular) and (c) tyre orientation on the 20 physiological and biomechanical responses to submaximal and maximal effort propulsion 21 specific to wheelchair basketball. 8 able-bodied individuals participated in the laboratory22 based testing, which took place on a wheelchair ergometer at two fixed speeds $\left(1.1 \& 2.2 \mathrm{~m} \cdot \mathrm{s}^{-}\right.$ $23^{1}$ ). Outcome measures were power output and physiological demand (oxygen uptake \& heart 24 rate). 3 participants with experience of over-ground sports wheelchair propulsion also 25 performed $2 \times 20$ m sprints in each wheel configuration. Results revealed that wheels differed 26 significantly in lateral stiffness with the 'new' Spinergy wheel shown to be the stiffest (678.2 $27 \pm 102.1 \mathrm{~N} \cdot \mathrm{mm}^{-1}$ ). However the effects of stiffness on physiological demand were minimal 28 compared to tyre type whereby tubular tyres significantly reduced the rolling resistance and 29 power output in relation to clincher tyres. Therefore tyre type (and subsequently inflation 30 pressure) remains the most important aspect of wheel specification for athletes to consider 31 and monitor when configuring a sports wheelchair.

32 Keywords: wheelchair configuration; mobility performance, wheelchair propulsion 


\section{Introduction}

It has been well documented over recent years how wheelchair configuration can affect performance in wheelchair sports, such as wheelchair basketball [1]. Research has typically focused on how major areas of configuration such as the size $[2,3]$ and camber angle [4-6] of the main wheels influence athletes mobility performance. However, there are numerous other features of a sports wheel that may also affect the ergonomics of sports wheelchair propulsion. Wheels currently available to athletes differ in the number, thickness, material and orientation of the spokes, which according to the cycling literature can affect the stiffness of a wheel [7-9].

Wheel stiffness refers to a wheels resistance to deflection under loading [7]. From the cycling literature, Minguez and Vogwell [9] revealed that a reduction in the number of spokes (from 18 to 12) reduces the radial stiffness of wheels. Alternatively, Gavin [8] suggested that increasing the thickness of the spokes (1.6 to $2.0 \mathrm{~mm}$ ) increases the radial and lateral stiffness of wheels. The material of wheel spokes also differ with steel thought to provide a stronger, fatigue-resistant spoke compared to aluminium or titanium [7]. However, the introduction of composite fibre materials offers a lighter, more expensive alternative [7]. Finally, the orientation of the spokes is also thought to impact wheel stiffness [8]. Wheels can be distinguished by the number of times one spoke is crossed by others (typically 0x [radially spoked], $2 \mathrm{x}, 3 \mathrm{x}$ or $4 \mathrm{x}$ ) with a greater number of crossings thought to reduce wheel stiffness [8]. Although the majority of the cycling literature has focused on the radial stiffness of the wheel, a key difference in sports wheelchairs is the $15-24^{\circ}$ camber angle of the main wheels [5]. Therefore a large percentage of the load placed on the wheel is not radial, suggesting that lateral stiffness would be a more appropriate measure for a sports wheelchair wheel.

Few studies have investigated different spoke configurations specific to wheelchair users $[10,11]$. Comparisons have been made between Spinergy wheels, which incorporate composite fibre spokes, in relation to conventional steel-spoked wheels [10,11]. However no improvement in physiological demand [10] or reduction in vibrations [11] was identified in Spinergy wheels, despite the perceived improvement in ride comfort [10]. Although no performance benefits were observed, details on the specific differences in wheel specifications, aside from spoke material, were not provided. In order to optimise performance through wheel specification, details of individual components need to be examined to establish reliable cause and effect relationships. It is also worth noting that both 
these studies were conducted from a daily-life perspective and as such translations to an athletic population are not possible. Another important consideration for the wheelchair user is wheelchair maintenance, since a poorly maintained wheelchair can increase the physical strain placed on the user [12]. Therefore it would also be of interest to quantify the impact that a reduction in spoke tension, which occurs over time in a used wheel, could have on wheel stiffness and subsequently performance.

In addition to wheel stiffness, wheels currently available to athletes also differ in tyre type and subsequent inflation pressure. Such parameters have again been investigated under conditions specific to daily-life wheelchair propulsion and have demonstrated that pneumatic tyres reduced the physiological demand compared to solid tyres [13,14]. These studies also revealed that power requirements and physiological demand both increase when tyre pressure drops to $25 \%$ [14] and 50\% [13,15] of the recommended inflation pressure. Pneumatic tyres are the popular choice for athletes participating in wheelchair basketball, however the tyres themselves can differ in their construction. Clincher tyres are most common, whereby the tyre extends from both walls of the wheel rim to partially encompass an inner tube [7]. However, an increasing number of athletes are selecting tubular tyres, which do not require an inner tube as the tyre is completely enclosed and sits within the walls of the wheel rim [7]. Tubular tyres enable a higher inflation pressure and are thought to be less prone to punctures [7].

As mentioned previously, the main wheels of a sports wheelchair are cambered, which can deform the tyre and increase resistance [5]. Recently manufacturers such as Celeritas 300 (Den Haag, Netherlands) have introduced novel developments to the wheel rim in an attempt to optimally orientate the tyre so that deformation and resistance are minimised. Yet to the authors knowledge, the impact of tyre orientation on aspects of mobility performance have not be investigated.

The aims of the current investigation were to: 1) explore the lateral stiffness of different sports wheelchair wheels commercially available to athletes in a 'new' and 'used' condition; and 2) determine the influence of (a) wheel stiffness, (b) tyre type (clincher vs. tubular) and (c) tyre orientation on the physiological and biomechanical responses to submaximal wheelchair propulsion and on maximal effort propulsion specific to wheelchair basketball. It was hypothesised that stiffer wheels would result in reduced physiological demand, since less energy would be dissipated through the wheel. Tubular tyres were 
hypothesised to reduce rolling resistance through their higher inflation pressure, which was expected to minimise physiological demand and improve maximal effort sprinting performance. This effect was hypothesised to improve further still when the tyres were orientated optimally by an innovative wheel rim design.

Methods

Participants

Eight able-bodied $(\mathrm{AB})$ males (age $=30 \pm 5$ years; body mass $=80.5 \pm 9.1 \mathrm{~kg}$; height $=1.81 \pm 0.06 \mathrm{~m}$ ) with previous experience of laboratory-based modes of wheelchair propulsion participated in the laboratory testing in the current study. A further three participants (age $=28 \pm 8$ years; body mass $=78.0 \pm 10.0 \mathrm{~kg})$ with extensive experience $(\geq 6$ years) of over-ground sports wheelchair propulsion participated in the field-based testing only. The study was approved by the local ethical committee and all participants provided their written, informed consent prior to testing.

Wheels

Three pairs of wheels currently available to wheelchair basketball players (i) Spinergy SLX, Spinergy Inc, San Diego, USA; (ii) Sun Equalisers, Sun Components, Milwaukee, USA; and (iii) Sun Classics, Sun Components, Milwaukee, USA; in both a 'new' and 'used' condition were investigated. In the used condition, spoke tensions were reduced and equated to the spoke tension of a 12 month old wheel, which were verified using a tensionmeter (Park Tool TM-1, Minnesota, USA). Each of these wheels were fitted with Kenda Kontender clincher tyres (Kenda, Ohio, USA), inflated to 110 psi.

Two further pairs of wheels (Spinergy SLX and Celeritas 300 wheel) equipped with tubular TUFO tyres (TUFO, Otrokovice, Czech Republic) were also investigated. TUFO

124 tyres are manufactured using a silicon tread compound and do not contain an inner tube 125 enabling a higher inflation pressure, which was controlled at 160 psi. As previously 126 mentioned, the Celeritas 300 incorporates an innovative design at the wheel rim-tyre interface. 127 The lateral wall of the rim is slightly higher in an attempt to orientate the tyre at an optimal position with the ground in a cambered wheelchair (Figure 1). The same chromium hand-rims 
129 were used with each wheel configuration. Further details of each wheel are provided in Table 1301.

Experimental Design

i) Wheel stiffness

The lateral stiffness of each wheel was examined using a deflection test (Figure 2).

138 During the deflection tests the wheel was supported at three contact points on the inside of 139 the wheel rim. Three incremental loads (5, 10 and $20 \mathrm{~kg}$ ) were then applied to the axle of the 140 wheel with the resulting deflection reported to the nearest $0.01 \mathrm{~mm}$ using a metric dial test 141 indicator gauge (Toolzone, Devon UK). Each wheel was tested twice with the contact points 142 in line with the spokes and twice with the contact points in between the spokes. Lateral 143 stiffness, expressed in $\mathrm{N} \cdot \mathrm{mm}^{-1}$, for each load and position was then averaged over 24 trials for 144 each wheel. A higher value represents a stiffer wheel.

\section{ii) Laboratory testing}

Participants performed a series of 3-minute bouts on a dual-roller wheelchair ergometer (VPHandisport-25, Tecmachine, France) at two submaximal speeds (1.1 and 2.2 $\mathrm{m} \cdot \mathrm{s}^{-1}$ ). All testing was performed on a single roller to minimise resistance, which were 152 equipped with two electromagnetic brakes, the sensors of which were calibrated using a 153 known weight at the beginning of each day. Speed and torque signals sampled at $100 \mathrm{~Hz}$. The 154 same basketball wheelchair (RGK Quattro, Burntwood, UK; 26 inch wheels, 18 camber, $15512.9 \mathrm{~kg}$ ) was used for all wheel configurations. Since a total of sixteen, 3-minute bouts were 156 to be performed (eight wheels, two speeds), each pair of wheels were tested in a randomised 
157 order over two separate sessions within a two-week period to minimise the influence of 158 fatigue.

Prior to each trial participants performed a deceleration test on the ergometer, 160 whereby they accelerated the wheelchair over five pushes before allowing the wheels to 161 decelerate to a standstill whilst sat upright and stationary. This enabled residual torque to be calculated, which is representative of rolling resistance. During each 3-minute trial participants averaged the desired speed, which was fed back in real time through a computer monitor (HP Compaq LA1951g, Hewlett Packard, California, USA) interfaced with the ergometer.

Data was collected during the final minute of each 3-minute trial. Power output was calculated using the average speed multiplied by the rolling resistance of the wheelchair-user combination. Expired air was collected using a breath-by-breath system (Cortex Metalyser 3B, Cortex, Leipzig, Germany), which had been calibrated at the beginning of each session using a known volume and concentration of gas. Respiratory data was recorded at $1 \mathrm{~Hz}$, with

171 oxygen uptake ( $\left.\mathrm{V}_{2}\right)$ averaged over the final minute. Heart rate was monitored using radio 172 telemetry (RS400 Polar Sport Tester, Kempele, Finland) and was averaged over 5-second 173 intervals. Push time and push frequency were also calculated during the final minute of each 174 trial. Using a customised MATLAB programme, push time was calculated as the period of 175 time during which a positive power output was produced. Push frequency was calculated by 176 dividing the number of complete pushes during the final minute by the time elapsed. On 177 completion of each 3-minute trial participants provided a measure of their localised, 178 centralised and overall rating of perceived exertion (RPE) using a Borg scale [16]. A rest 179 period of 3-minutes was provided between each trial to eliminate the effects of fatigue. To 180 ensure fatigue was not present, the first trial of each session was repeated at the end, which 181 verified the absence of fatigue.

\section{iii) Field testing}

Each wheel configuration was also tested during maximal effort, on-court wheelchair propulsion, specific to wheelchair basketball on a separate occasion. Field testing was 
standstill in each wheel configuration. Wireless timing gates (Brower, Utah, USA) were positioned after 2.5 and $5 \mathrm{~m}$ to explore the influence of wheel configuration on initial acceleration and after $20 \mathrm{~m}$ to examine maximal sprinting performance. A 90-second rest period was enforced between each sprint.

\section{Statistical Analysis}

Means and standard deviations (SD) were computed for all variables during each wheel configuration. Data from the stiffness and laboratory-based testing was analysed using the Statistical Package for Social Sciences (SPSS version 21.0, Chicago, IL, USA) and was assessed for normality using Shapiro Wilk’s tests. A repeated measures analysis of variance (ANOVA) was used to determine whether lateral stiffness differed between wheel configurations. Significant main effects were explored using pairwise comparisons with a Bonferroni adjustment. Differences in stiffness when measured in line and in between spokes were examined using paired sample t-tests. A repeated measures ANOVA was performed for each laboratory-based measure to assess the effect of wheel configuration on submaximal wheelchair performance. Stiffness comparisons were made between and within new and used wheels. Tyre type comparisons were made between the new wheels with clincher tyres and the Spinergy TUFO and Celeritas 300 (both tubular), whilst tyre orientation comparisons were made between Spinergy TUFO and Celeritas 300. Pairwise comparisons were used to identify where any significant differences existed between wheel configurations using a Bonferroni adjustment. Effect sizes (ES) were calculated for statistically significant pairwise comparisons and were categorised as trivial $(<0.2)$, small $(\geq 0.2-0.6)$, moderate $(\geq 0.6-$ $1.2)$, large $(\geq 1.2-2.0)$ and very large $(\geq 2.0)$ according to previous guidelines [17].

Results

As demonstrated in Figure 3, lateral stiffness differed across wheel configurations ( $P$ $215<0.0005)$. Pairwise comparisons identified a significant $(P<0.0005$; ES $=7.6)$ reduction in 216 lateral stiffness between the new $\left(545.5 \pm 20.1 \mathrm{~N} \cdot \mathrm{mm}^{-1}\right)$ and used $\left(430.0 \pm 7.4 \mathrm{~N} \cdot \mathrm{mm}^{-1}\right)$ 217 Classic wheel. The new Classic wheel also elicited a significantly lower stiffness value than 
218 both the new Spinergy $\left(678.2 \pm 102.1 \mathrm{~N} \cdot \mathrm{mm}^{-1} ; P=0.008\right.$; ES = 1.8) and Equaliser $(579.7 \pm$ $21915.8 \mathrm{~N} \cdot \mathrm{mm}^{-1} ; P<0.0005$; ES = 1.9) wheels. Similarly in a used condition, the Classics lateral 220 stiffness was significantly lower than the used Spinergy $\left(589.9 \pm 23.6 \mathrm{~N} \cdot \mathrm{mm}^{-1} ; P<0.0005\right.$; 221 ES = 9.1) and Equaliser $\left(578.9 \pm 13.0 \mathrm{~N} \cdot \mathrm{mm}^{-1} ; P<0.0005 ; \mathrm{ES}=14.1\right)$ wheels. The Celeritas 222300 wheel differed in stiffness to all other wheel configurations. Greater stiffness was 223 revealed in the Celeritas 300 wheel $\left(456.3 \pm 8.2 \mathrm{~N} \cdot \mathrm{mm}^{-1}\right)$ than the used Classic wheel $(P<$ 224 0.0005; ES = 3.4), with reduced stiffness demonstrated in relation to all other wheel 225 configurations $(P<0.0005$; ES $=3.1$ to 11.3$)$.

FIGURE 3

The Spinergy wheel was identified as the stiffest wheel tested, however as illustrated in Figure 3 large standard deviations were observed for this wheel in the new condition. This could be attributed to the significantly greater lateral stiffness $(P=0.002$; ES $=4.6)$ observed for the new Spinergy wheel ‘in line’ compared to ‘in between’ spokes (Table 2). The Classic wheel also demonstrated significantly greater stiffness 'in line' with the spokes in both the new $(P=0.017 ; \mathrm{ES}=2.1)$ and used $(P=0.042 ; \mathrm{ES}=1.2)$ conditions.

TABLE 2

Wheel configuration had a significant main effect on the residual torque and the 239 power output of wheelchair propulsion at both low and high speeds $(P<0.0005)$. Residual torque and consequently the power output were significantly lower in both the tubular types, 241 Spinergy TUFO and Celeritas 300, $(P \leq 0.006$; ES $=\geq 2.36)$ compared to all other wheel 242 configurations with clincher tyre types (Figure 4). 
Despite the differences in stiffness and residual torque, minimal differences in 248 physiological and biomechanical parameters were observed between wheel configurations. A 249 significant effect of wheel configuration on $\dot{\mathrm{VO}}_{2}$ was observed at both low $(P=0.001)$ and 250 high $(P=0.018)$ speeds (Figure 5$)$. During the low speed, $\dot{\mathrm{VO}}_{2}$ was significantly lower in the 251 Celeritas 300 wheel $\left(0.60 \pm 0.11 \mathrm{~L} \cdot \mathrm{min}^{-1}\right)$ than in the new Spinergy $\left(0.74 \pm 0.12 \mathrm{~L} \cdot \mathrm{min}^{-1} ; P=\right.$ 252 0.045; ES = 1.2), used Spinergy $\left(0.75 \pm 0.11 \mathrm{~L} \cdot \mathrm{min}^{-1} ; P=0.047\right.$; ES = 1.4) and used 253 Equaliser $\left(0.74 \pm 0.10 \mathrm{~L} \cdot \mathrm{min}^{-1} ; P=0.049\right.$; ES $\left.=1.3\right)$. During the high speed, no statistically significant pairwise comparisons were identified between wheel configurations for $\dot{\mathrm{V}}_{2}$ 255 although differences approaching significance existed between the Celeritas 300 wheel ( 0.98 $\left.256 \pm 0.18 \mathrm{~L} \cdot \mathrm{min}^{-1}\right)$ and both the used Spinergy $\left(1.19 \pm 0.19 \mathrm{~L} \cdot \mathrm{min}^{-1} ; P=0.056\right.$; ES $\left.=1.1\right)$ and 257 Classic $\left(1.15 \pm 0.18 \mathrm{~L} \cdot \mathrm{min}^{-1} ; P=0.059\right.$; ES $\left.=0.9\right)$ wheel. No significant effect of wheel 258 configuration was identified for heart rate during the low speed $(P=0.349)$. At the high 259 speed, a significant main effect was observed for heart rate $(P=0.020)$, although no significant pairwise comparisons existed. Differences approaching statistical significance were again identified between the Celeritas 300 wheel $\left(94 \pm 11\right.$ beats $\left.\mathrm{min}^{-1}\right)$ and the new (101 $\pm 9 \mathrm{~L} \cdot \mathrm{min}^{-1} ; P=0.066$; ES $\left.=0.7\right)$ and used $\left(101 \pm 9 \mathrm{~L} \cdot \mathrm{min}^{-1} ; P=0.085\right.$; ES $\left.=0.7\right)$ Spinergy wheel. Wheel configuration had no significant bearing on localised, centralised and overall RPE, push time or push frequency at either speed.

\section{FIGURE 5}

\section{iii) $\quad$ Field testing}

The results of the $20 \mathrm{~m}$ sprints are displayed in Figure 6. The most noticeable differences in initial acceleration performance over $2.5 \mathrm{~m}$ (Figure 6a) and $5 \mathrm{~m}$ (Figure 6b) seemed to occur between the Spinergy wheels. The new Spinergy wheels displayed quicker times over $2.5 \mathrm{~m}(1.24 \pm 0.10 \mathrm{~s})$ and $5 \mathrm{~m}(2.03 \pm 0.14 \mathrm{~s})$ compared to the used Spinergy wheels $(1.29 \pm 0.09 \mathrm{~s} ; 2.08 \pm 0.14 \mathrm{~s}$ respectively). Yet at $20 \mathrm{~m}$ no differences appeared to exist (Figure 6c). The Equaliser wheels revealed the quickest times across all distances and

275 the condition of this wheel (new or used) had little effect on performance. Finally, tubular 
276 tyres did not appear to have a beneficial effect on linear sprinting performance. In fact, times 277 were quicker in the new Spinergy, with clincher tyres, over $2.5 \mathrm{~m}$ (1.24 $\pm 0.10 \mathrm{~s}), 5 \mathrm{~m}$ (2.03 \pm $2780.14 \mathrm{~s})$ and $20 \mathrm{~m}(5.72 \pm 0.33 \mathrm{~s})$ compared to the new Spinergy with tubular TUFO tyres $279(1.27 \pm 0.14 \mathrm{~s} ; 2.09 \pm 0.23 \mathrm{~s} ; 5.86 \pm 0.38 \mathrm{~s}$ respectively). In the comparison of tyre orientation, 280 the Spinergy TUFO demonstrated slightly quicker times than the Celeritas 300 wheel over $2812.5 \mathrm{~m}(1.29 \pm 0.15 \mathrm{~s})$ and $5 \mathrm{~m}(2.12 \pm 0.23 \mathrm{~s})$, yet slower times over $20 \mathrm{~m}(5.77 \pm 0.38 \mathrm{~s})$.

FIGURE 6

\section{Discussion}

Wheels currently available to wheelchair basketball players differed in lateral stiffness. However, the impact that these wheels had on aspects of submaximal and maximal effort sports wheelchair propulsion were minimal. Alternatively, tyre type appeared to have more of an impact on performance, with high pressure tubular tyres shown to reduce rolling resistance and physiological demand. No further improvements in submaximal or maximal effort performance were established through innovative tyre orientations.

Wheel stiffness

The deflection tests revealed that Spinergy wheels were the stiffest $(678.2 \pm 102.1$ $295 \mathrm{~N} \cdot \mathrm{mm}^{-1}$ ) new wheels investigated. However, statistically significant differences were only 296 identified in relation to the Classic and Celeritas 300 wheels. The fact that no significant difference was identified between the Spinergy and the Equaliser $\left(579.7 \pm 15.8 \mathrm{~N} \cdot \mathrm{mm}^{-1}\right)$ wheels could be attributed to the large standard deviations observed for the new Spinergy's. 299 The Spinergy wheels were found to be significantly stiffer when measured in line with the spokes compared to in between spokes. The rationale for the greater stiffness in line with the spokes could be attributed to the different material, greater thickness or radial orientation of 302 the spokes in a Spinergy wheel. The fact that lateral stiffness decreased in between spokes was likely to be related to the reduced number of spokes the Spinergy's possessed (24) and subsequently the greater distances between spokes. Such a decrease in stiffness was not 
305 observed in between spokes for the Equaliser, which contain double the number of spokes 306 (48).

307 Despite this, it was clear that both the Spinergy and Equaliser wheels were 308 significantly stiffer than the Classic and Celeritas 300 wheels in a new condition. Upon 309 inspection of the specifications of each of these wheel configurations (Table 1), it was 310 possible that the orientation of the spokes attributed to the differences observed. Both the 311 Classic and Celeritas 300 wheels contained the same number (36) of spokes which were 312 crossed (3x) on both sides of the wheel. Therefore the absence of radially orientated spokes, 313 which were present on both sides in the Spinergy and on the inside of the Equaliser, could 314 contribute to the lower stiffness. Gavin [8] revealed that the greater the number of spoke 315 crossings, the lower the radial and lateral stiffness, which would support the aforementioned 316 statement. Even though the Equalisers contain 4x crossings, this was only on the outside of 317 the wheel and it appeared that the radial orientation of the inside spokes (0x) were sufficient 318 for ensuring a stiff wheel. Gavin [8] also revealed that thicker spokes increased the radial and 319 lateral stiffness of a bicycle wheel, which could further indicate the superior stiffness of the 320 Spinergy wheel, which at $4 \mathrm{~mm}$, were far thicker than the steel spokes of all other wheel 321 configurations.

A comparison of wheels in both a new and used condition revealed a decline in lateral 323 stiffness in the Spinergy and Classic wheels in the used condition. Such deterioration was not 324 observed for the Equalisers, which appeared to maintain their stiffness over time. These 325 findings could again be explained by the number of spokes possessed by each wheel, 326 whereby the wheel with the greater number of spokes maintains its stiffness over time even 327 when the tension of individual spokes are reduced. However, this effect was exacerbated in 328 wheels containing fewer spokes, where the distance between spokes obviously increases. 329 This could have practical implications on wheelchair maintenance, as it would appear that 330 constantly monitoring and maintaining spoke tension is more important in wheels with fewer 331 spokes (Spinergy's and Classic's) than in wheels with a greater number of spokes 332 (Equaliser's). 
Despite the aforementioned differences in lateral stiffness between wheel configurations and the rationale for these differences, wheel stiffness appeared to have little effect on physiological demand or propulsion technique. The only physiological differences that existed between wheel configurations occurred in relation to the new Celeritas 300 wheel, which were equipped with high pressure tubular tyres. Of particular interest were the significant differences in $\mathrm{VO}_{2}$ identified at the low speed and the meaningful differences in heart rate observed at the high speed between the Celeritas 300 wheel and the new Spinergy. As previously mentioned, the new Spinergy was established as the stiffest wheel available, whereas the Celeritas 300 wheel was found to be the least stiff $\left(456.3 \pm 8.2 \mathrm{~N} \cdot \mathrm{mm}^{-1}\right)$ of the new wheels investigated. This would suggest that tyre type (and inflation pressure) has a far greater impact on performance than wheel stiffness. The fact that no further improvements in performance were achieved when the tubular TUFO tyre was tested in the stiffest wheel (Spinergy TUFO) confirmed this. Therefore minimising rolling resistance remains the critical factor in maximising pushing economy, which was not affected by lateral wheel stiffness, but was reduced in the higher pressure tubular TUFO tyres. This confirms the physiological benefits of higher tyre pressures that have previously been identified during daily life wheelchair propulsion [13-15] and highlights how important it is for athletes to constantly monitor their tyre pressure.

The results of the field-based testing revealed some interesting trends with regards to the effect of wheel configuration on initial acceleration and maximal effort linear sprinting performance. One of the most noticeable trends identified was the change in performance of the Spinergy wheels between the new and used condition. Over $2.5 \mathrm{~m}$ and $5 \mathrm{~m}$, the new Spinergy wheel elicited quicker times than the used wheel, however no difference was observed at $20 \mathrm{~m}$. It could therefore be interpreted that a stiffer wheel (new Spinergy) facilitates initial acceleration performance, but then a slightly more flexible wheel (used Spinergy) facilitates overall sprinting performance. Brandt [7] suggested that radial spokes cannot transmit torque as effectively as crossed spokes, as torque is only created once the hub rotates ahead of the rim, causing a small offset. This offset, which worsens when spoke tension is reduced, could lead to energy loss during the push and may account for the slightly impaired acceleration performance in the used Spinergy, where spoke tensions were reduced [7]. However, the same pattern was also observed in the Classic wheels, where the newer (stiffer) wheel appeared slightly quicker over short distances, yet similar over $20 \mathrm{~m}$. 
between the new and used condition may also bring about a loss in energy during initial acceleration. Similarly the stiffer Spinergy TUFO was slightly quicker over $2.5 \mathrm{~m}$ and $5 \mathrm{~m}$ compared to the Celeritas 300 wheel, also equipped with TUFO tyres. However, at $20 \mathrm{~m}$ this pattern had reversed and the more flexible Celeritas 300 wheel displayed quicker times.

372 Explanations for the apparent improvement in linear sprinting after initial acceleration and 373 inertia had been overcome remain unclear and worthy of further investigation.

The wheel which appeared to perform the best across all distances of the $20 \mathrm{~m}$ sprint was the Equaliser, where no real differences were seen between the new and used condition. The fact that no differences were observed between the new and used Equaliser could be due to the fact that these wheels did not differ in stiffness as previously mentioned. The only plausible rationale for the apparent superior performance could be due to the greater consistency in stiffness all around the Equaliser wheels, since no decline in stiffness was established in between spokes. However, further research would again be required to explore this association.

Contrary to the laboratory-based testing and what was originally hypothesised, the tubular TUFO tyres did not seem to equate to beneficial on court performance. In fact it appeared as if these high pressure tyres actually impeded linear sprinting performance since times were slightly slower across all distances of the $20 \mathrm{~m}$ sprint in the Spinergy TUFO compared to the new Spinergy with clincher tyres. Therefore, the greater tyre pressure of the TUFO tyres (160 psi), which effectively reduced rolling resistance and physiological demand in a laboratory environment, may have reduced the rolling resistance too much to allow for effective performance in a sporting environment. It appeared as though the tyre pressure may actually be too high (and the resistance too low) to enable sufficient traction between the tyre and the surface to translate to successful on court performance. This is a slight concern given that the TUFO tyres can be inflated to as much as 230 psi. It would appear that further research is required to identify optimal tyre pressures, as there seems to be a point where high pressure tyres that minimise rolling resistance and physiological demand become too high to provide athletes with enough grip on a sports hall surface. As we already know from previous literature the rolling resistance experienced in a sports wheelchair is lower during overground propulsion on a basketball court surface compared to laboratory-based modalities [18].

Although tubular tyres elicited a positive effect on rolling resistance and physiological 
400 innovative wheel rim design (Celeritas 300) appeared to have no further influence on 401 performance. The Celeritas 300 was designed specifically for wheelchair sports with the 402 intention of orientating the tyre in a position that would reduce tyre deformation and 403 resistance in cambered sports wheelchairs. However, when compared to the Spinergy TUFO, 404 which was equipped with the same high pressure tubular tyres, no further reductions in 405 resistance or physiological demand were observed in the Celeritas 300. Despite this, athletes 406 who participated in the field testing did comment favourably on the performance of the 407 Celeritas 300. After completing the $20 \mathrm{~m}$ sprint, participants had to turn and return to the start 408 line for the next trial. It was during this manoeuvre that participants felt the Celeritas 300 409 excelled with turning at high speeds said to be facilitated. Obviously manoeuvrability 410 performance was not investigated during the current study, however such comments suggest 411 this may be a useful area for future investigation. Although tyre orientation did not 412 significantly reduce rolling resistance to the benefit of laboratory-based or linear court-based 413 propulsion, it may reduce turning resistance, which could benefit wheelchair basketball 414 players.

\section{Future recommendations}

Despite all of the interesting trends identified within the field-based testing, it must be reiterated that a sample size of only 3 participants prevented any statistical analysis. 419 Therefore, future research with a larger sample of athletes would be warranted to confirm or 420 refute the initial findings presented. Based on what has been reported it would appear that 421 lateral wheel stiffness has little impact on submaximal pushing economy, however potential 422 improvements in initial acceleration performance could be achieved from a stiffer wheel. 423 Alternatively top-end sprinting performance appeared inhibited in stiffer wheels. Such 424 information could be extremely valuable to wheelchair manufacturers to identify the optimal 425 wheel configuration in terms of stiffness, tyre type / pressure and orientation to maximise all 426 areas of performance. Given that the aim of the current investigation was to explore a range 427 of wheels currently available, wheels differed in a number of spoke components. Therefore, it 428 may be beneficial for future testing to manipulate one area of wheel specification in isolation 429 to determine reliable cause and effect relationships between the intervention and performance. 


\section{Conclusions}

432 The current study demonstrated that wheel configuration is an important consideration 433 for wheelchair athletes. Although wheels currently available to athletes do differ in lateral 434 stiffness, these differences have little effect on physiological demand. Whereas wheels with 435 high pressure tubular tyres significantly reduced physiological demand through a lower 436 rolling resistance. Therefore, it would appear that tyre type and pressure remain the most 437 important aspects of wheel configuration for athletes to consider and maintain when 438 purchasing a sports wheelchair.

439

440 
442 The authors would like to thank RGK wheelchairs for their support and provision of 443 equipment for the current study. Thanks are also extended to Loughborough Sports 444 Technology Institute and Bob Budge for their assistance with data collection.

\section{References}

447 [1] Mason BS, van der Woude LH, Goosey-Tolfrey VL. The ergonomics of wheelchair 448 configuration for optimal performance in the wheelchair court sports. Sports Med 2013; 43(1): 449 23-38.

450 [2] Mason BS, van der Woude LH, Tolfrey K, Lenton JP, Goosey-Tolfrey VL. Effects of 451 wheel and hand-rim size on submaximal propulsion in wheelchair athletes. Med Sci Sports 452 Exerc 2012; 44(1): 126-134.

453 [3] Mason BS, van der Woude LHV, Lenton JP, Goosey-Tolfrey VL. The effect of wheel 454 size on mobility performance in wheelchair athletes. Int J Sports Med 2012;33(10): 807-12.

455 [4] Faupin A, Campillo P, Weissland T, Gorce P, Thevenon A. The effects of rear-wheel 456 camber on the mechanical parameters produced during the wheelchair sprinting of 457 handibasketball athletes. J Rehabil Res Dev 2004; 41(3B): 421-8.

458 [5] Mason B, van der Woude L, de Groot S, Goosey-Tolfrey V. Effects of camber on the 459 ergonomics of propulsion in wheelchair athletes. Med Sci Sports Exerc 2011;43(2): 319-26.

460 [6] Mason B, van der Woude L, Tolfrey K, Goosey-Tolfrey V. The effects of rear-wheel 461 camber on maximal effort mobility performance in wheelchair athletes. Int J Sports Med 462 2012; 33(3): 199-204.

463 [7] Brandt J. The bicycle wheel. 3rd ed. California, USA: Avocet, Inc; 1993.

464 [8] Gavin HP. Bicycle wheel spoke patterns and spoke fatigue. J Eng Mech 1996; 122(8): 465 736-42.

466 [9] Minguez JM, Vogwell J. An analytical model to study the radial stiffness and spoke load 467 distribution in a modern racing bicycle wheel. J Mech Eng Sci 2008; 222(4): 563-76.

468 [10] Hughes B, Sawatzky BJ, Hol AT. A comparison of spinergy versus standard steel-spoke 469 wheelchair wheels. Arch Phys Med Rehabil 2005; 86(3): 596-601.

470 [11] Vorrink SN, Van der Woude LH, Messenberg A, Cripton PA, Hughes B, Sawatzky BJ. 471 Comparison of wheelchair wheels in terms of vibration and spasticity in people with spinal 472 cord injury. J Rehabil Res Dev 2008; 45(9): 1269-79. 
473 [12] Van der Woude LHV, Veeger HEJ, Dallmeijer AJ, Janssen TWJ, Rozendaal LA. 474 Biomechanics and physiology in active manual wheelchair propulsion. Med Eng Phys 2001; 475 23:713-33.

476 [13] Sawatzky B, Kim W, Denison I. The ergonomics of different tyres and tyre pressure 477 during wheelchair propulsion. Ergon 2004; 47(14): 1475-83.

478 [14] de Groot S, Vegter RJ, van der Woude LH. Effect of wheelchair mass, tire type and tire 479 pressure on physical strain and wheelchair propulsion technique. Med Eng Phys 2013; 35(10): 480 1476-82.

481 [15] Sawatzky BJ, Miller WC, Denison I. Measuring energy expenditure using heart rate to 482 assess the effects of wheelchair tyre pressure. Clin Rehabil 2005; 19(2): 182-7.

483 [16] Borg G. Perceived exertion as an indicator of somatic stress. Scand J Rehabil Med 1970; 484 2(2): 92-8.

485 [17] Batterham AM, Hopkin WG. Making meaningful inferences about magnitudes. Int J 486 Sports Physiol Perform 2006; 1: 50-7.

487 [18] Mason B, Lenton J, Leicht C, Goosey-Tolfrey V. A physiological and biomechanical 488 comparison of over-ground, treadmill and ergometer wheelchair propulsion. J Sports Sci 489 2013; 32(1): 78-91.

490

491

492

493 
495 Figure 1 - Illustration of the wheel rim design in a) the Celeritas 300 and b) standard 496 Spinergy wheel and the tyre orientation of both wheels

497

498 Figure 2 - The experimental set-up of the deflection test used to assess lateral stiffness in 499 each wheel configuration

500

501 Figure 3 - The effect of wheel configuration on lateral stiffness (means \pm SD).

502 Statistically significant differences are represented by:

$503 *$ between new and used wheels

$504{ }^{a}$ new Spinergy

$505{ }^{\mathrm{b}}$ new Equaliser

$506{ }^{\mathrm{c}}$ used Spinergy

$507{ }^{\mathrm{d}}$ used Equaliser

508 e all other wheel types

509

510 Figure 4 - The effect of wheel configuration on the residual torque and power output at two 511 submaximal speeds of wheelchair propulsion $(n=8)$. All values are means \pm SD.

$512 *$ *epresents a significant difference to Celeritas 300

513 \# represents a significant difference to Spinergy TUFO

514

515 Figure 5 - The effect of wheel configuration on oxygen uptake (top) and heart rate (bottom)

516 during two speeds of wheelchair propulsion $(n=8)$. All values are means \pm SD.

517 *represents a significant difference to Celeritas 300

519 Figure 6 - The effect of wheel configuration on linear sprinting performance over a) 2.5m; b)

$5205 \mathrm{~m}$ and c) $20 \mathrm{~m}$ during field based testing $(\mathrm{n}=3)$. All values are means \pm SD. 
Table 1 - Physical properties of the wheel configurations investigated

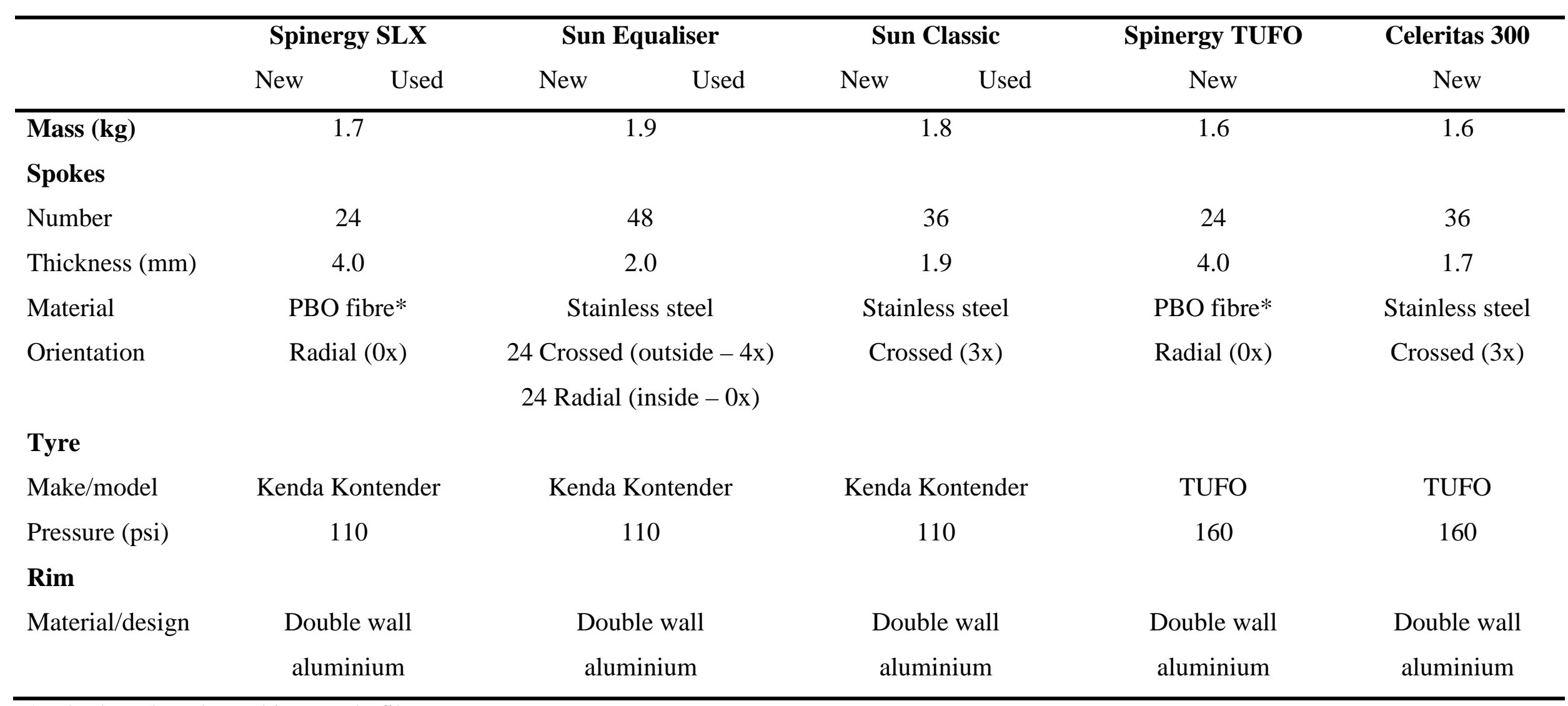

*polyphenylene bensobisoxazole fibre 
Table 2 -Lateral stiffness values (means \pm SD) of each wheel 'in line' and 'in between' spokes

\begin{tabular}{|c|c|c|c|c|}
\hline \multirow[t]{2}{*}{ Wheel } & \multirow[t]{2}{*}{ Condition } & \multicolumn{3}{|c|}{ Stiffness $\left(\mathrm{N} \cdot \mathrm{mm}^{-1}\right)$} \\
\hline & & In line & & In between \\
\hline \multirow[t]{2}{*}{ Spinergy } & New & $769.1 \pm 44.0$ & $*$ & $587.4 \pm 34.3$ \\
\hline & Used & $593.4 \pm 21.1$ & & $586.5 \pm 26.4$ \\
\hline \multirow[t]{2}{*}{ Equaliser } & New & $589.9 \pm 9.6$ & & $578.9 \pm 15.7$ \\
\hline & Used & $591.3 \pm 7.0$ & & $578.9 \pm 13.3$ \\
\hline \multirow[t]{2}{*}{ Classic } & New & $559.9 \pm 5.0$ & $*$ & $531.0 \pm 19.0$ \\
\hline & Used & $433.8 \pm 8.0$ & $*$ & $426.1 \pm 4.5$ \\
\hline Celeritas 300 & New & $460.1 \pm 6.9$ & & $452.4 \pm 8.0$ \\
\hline
\end{tabular}

*represents a statistically significant difference $(P<0.05)$ 


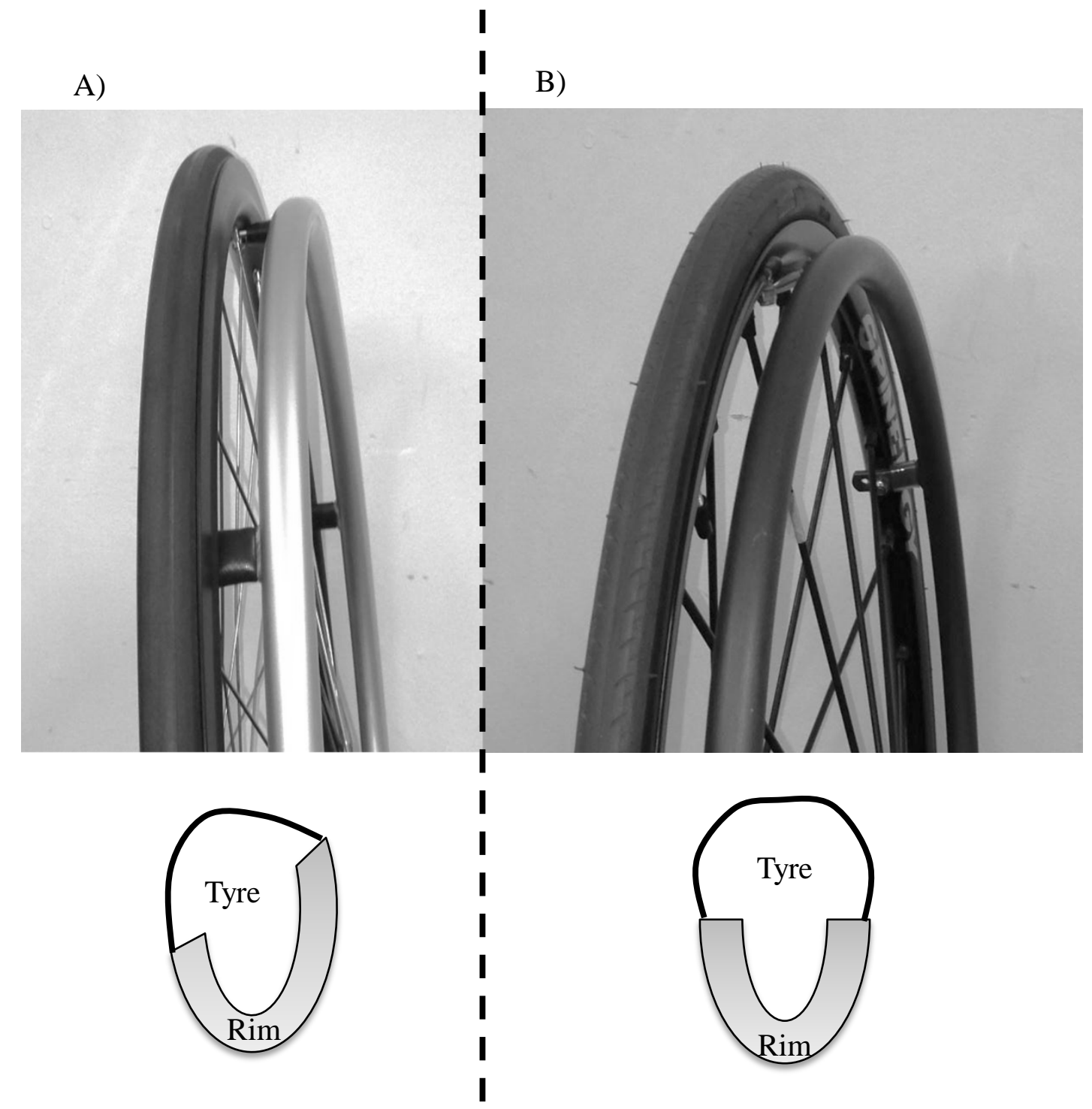




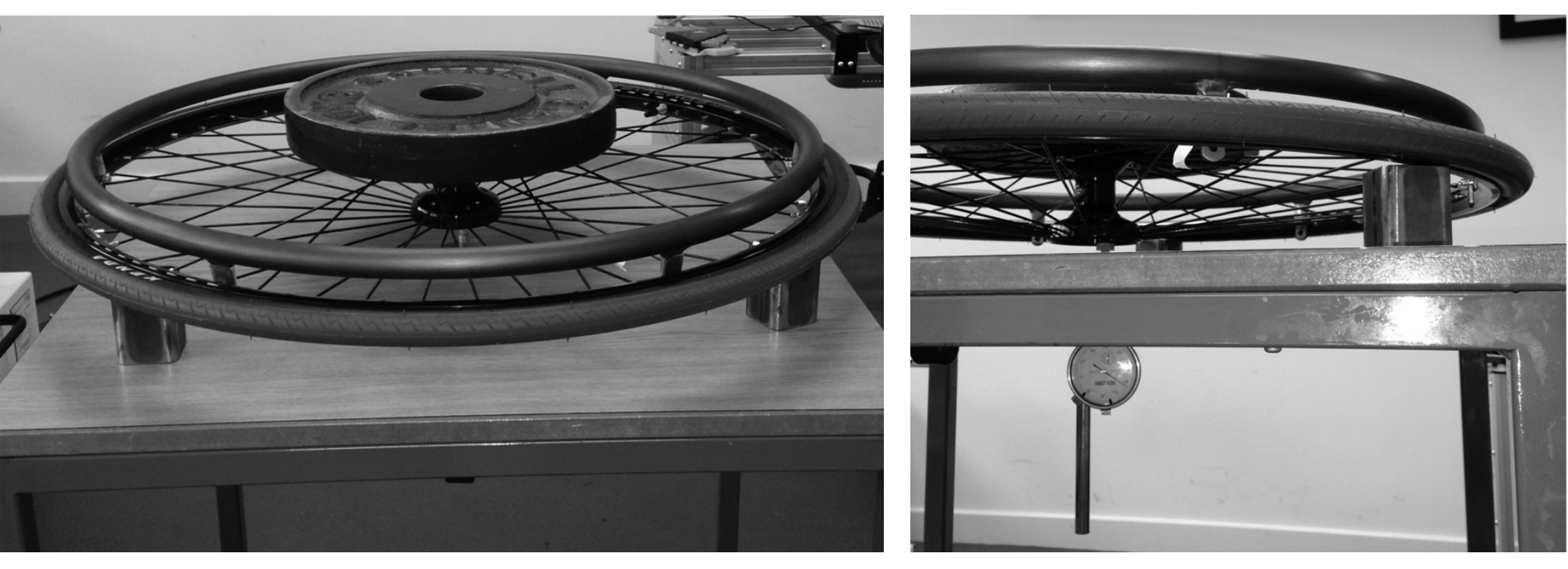


$\square$ New $\square$ Used

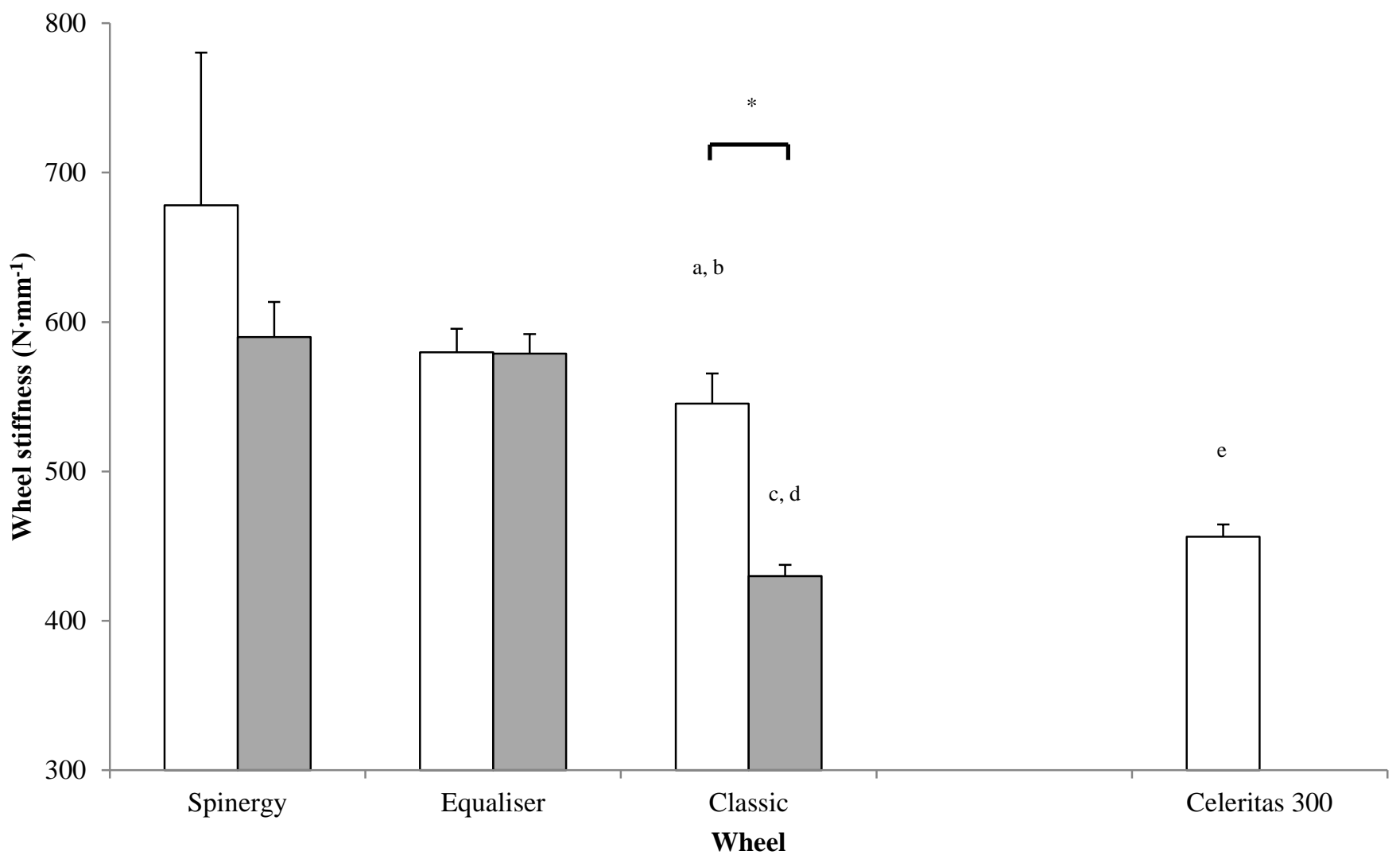


$\sqsubset$ Low $\square$ High $\quad \bullet-$ Residual torque

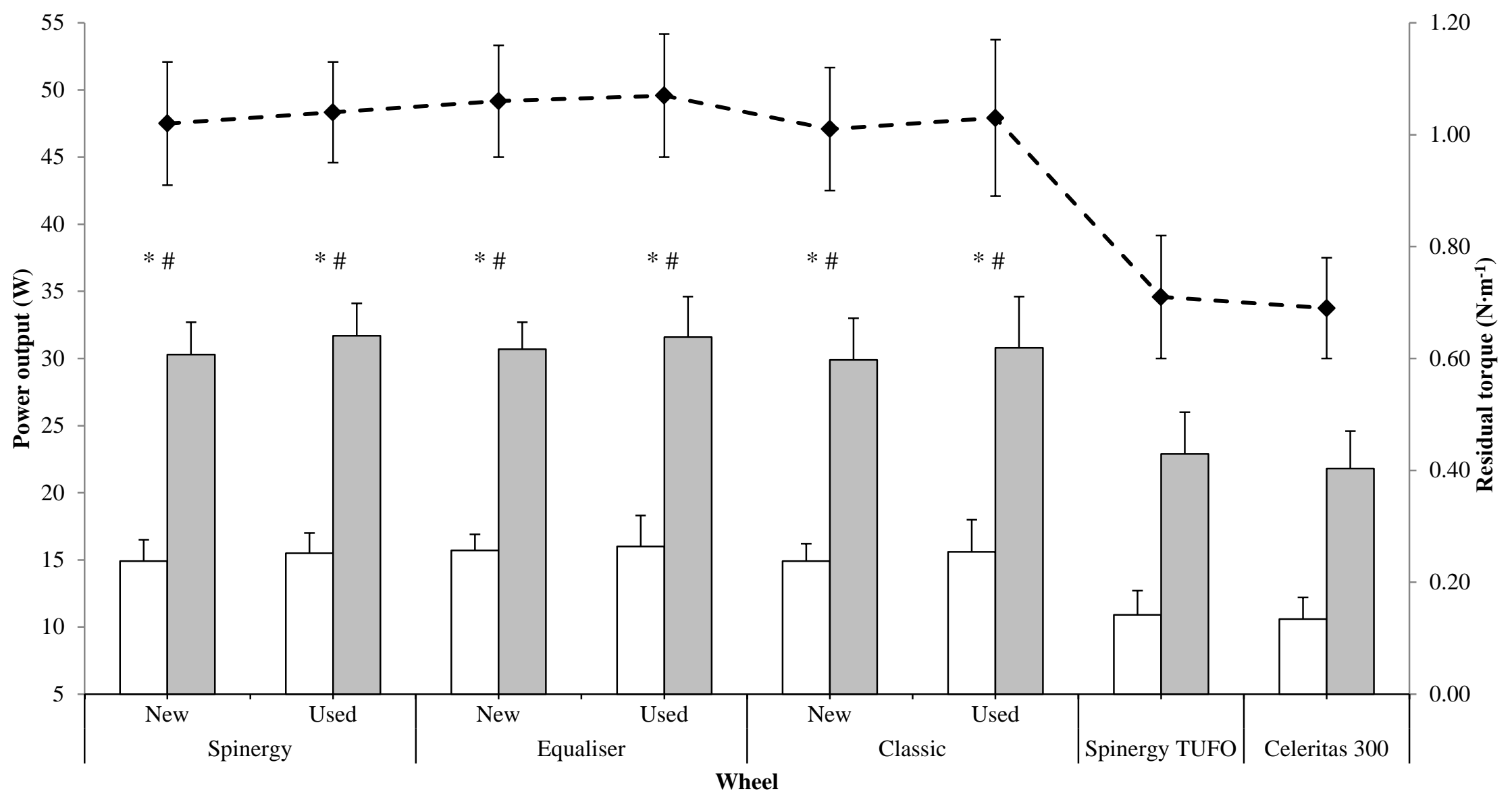


$\square$ Low $\square$ High
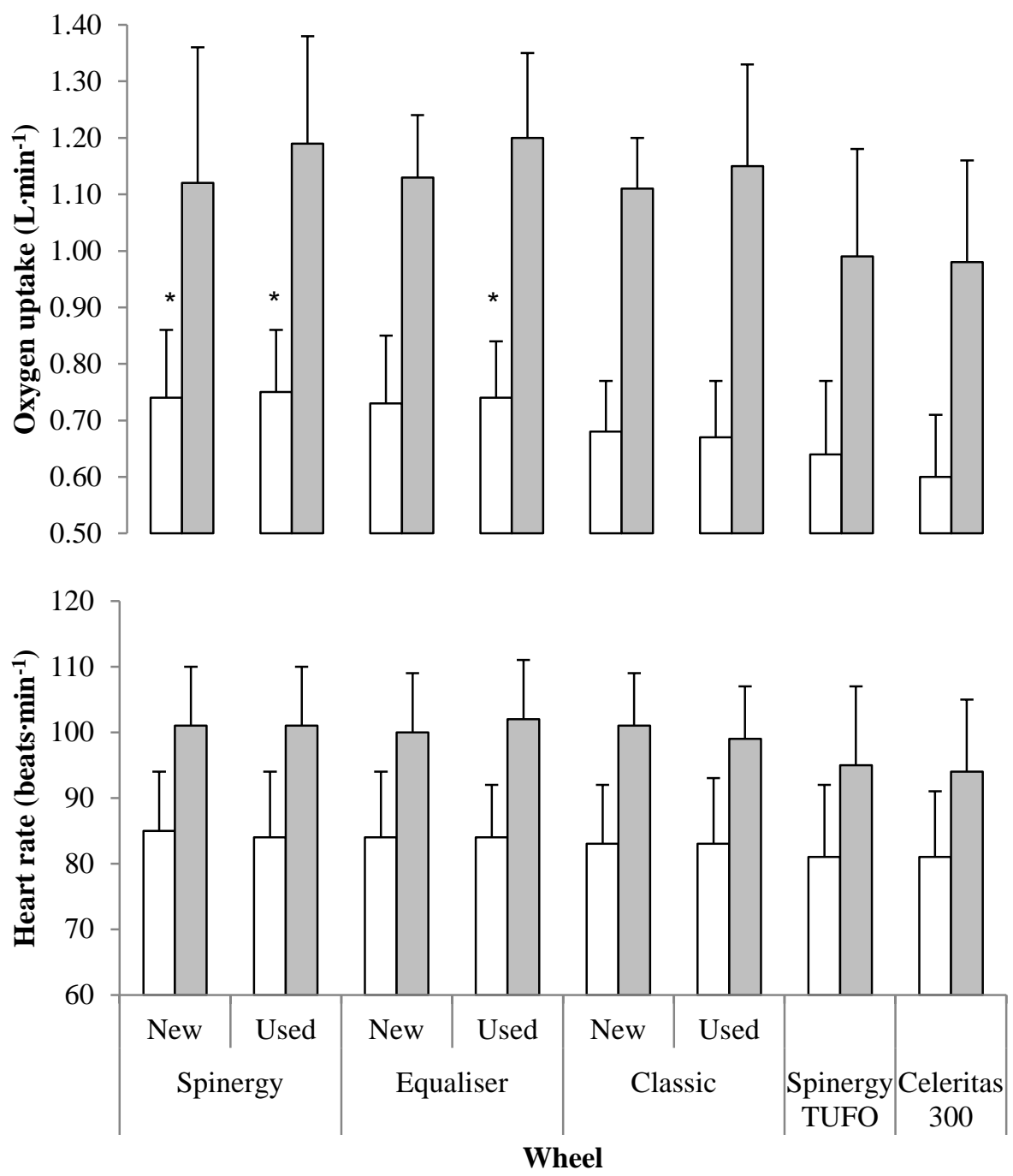
